\title{
Erratum: Aspects of boundary conditions for non-Abelian gauge theories [Phys. Rev. D 100, 045001 (2019)]
}

\author{
A. P. Balachandran, V. P. Nair, and Sachindeo Vaidya $\odot$ \\ (Q) (Received 27 September 2019; published 17 October 2019)
}

DOI: $10.1103 /$ PhysRevD.100.089901

Equation (36) should read

$$
\left\langle 0\left|J_{0}(x) Q(\mu)\right| 0\right\rangle=\left\langle 0\left|e^{i P \cdot x} J_{0}(0) e^{-i P \cdot x} Q(\mu)\right| 0\right\rangle=\text { constant. }
$$

Published by the American Physical Society under the terms of the Creative Commons Attribution 4.0 International license. Further distribution of this work must maintain attribution to the author(s) and the published articles title, journal citation, and DOI. 